\title{
Association between adipose tissue expression and serum levels of leptin and adiponectin in women with polycystic ovary syndrome
}

\author{
S.B. Lecke ${ }^{1,2}$, D.M. Morsch ${ }^{1,2}$ and P.M. Spritzer ${ }^{1,2}$ \\ ${ }^{1}$ Unidade de Endocrinologia Ginecológica, Serviço de Endocrinologia, \\ Hospital de Clínicas de Porto Alegre, Porto Alegre, RS, Brasil \\ ${ }^{2}$ Laboratório de Endocrinologia Molecular, Departamento de Fisiologia, \\ Universidade Federal do Rio Grande do Sul, Porto Alegre, RS, Brasil
}

Corresponding author: P.M. Spritzer

E-mail: spritzer@ufrgs.br

Genet. Mol. Res. 12 (4): 4292-4296 (2013)

Received July 27, 2012

Accepted November 10, 2012

Published February 28, 2013

DOI http://dx.doi.org/10.4238/2013.February.28.16

\begin{abstract}
We reviewed emerging evidence linking serum levels and adipose tissue expression of leptin and adiponectin in women with polycystic ovary syndrome (PCOS). Previous data obtained by our group from a sample of overweight/obese PCOS women and a control sample of normal weight controls, both stratified by BMI, were reanalyzed. Circulating levels of leptin and adiponectin were determined by commercially available enzyme-linked immunosorbent assays. Adipose tissue total RNA was reserve-transcripted into complementary DNA samples, which were used as templates for quantitative real-time PCR amplification. Positive correlations were found between serum and mRNA levels for both leptin ( $\mathrm{r}=$ $0.321 ; \mathrm{P}=0.005)$ and adiponectin $(\mathrm{r}=0.266 ; \mathrm{P}=0.024)$. Deter-
\end{abstract}


mination of leptin and adiponectin serum levels could serve as an indirect method to assess adipocyte production, since leptin and adiponectin are predominantly produced by subcutaneous adipocytes in women.

Key words: Adipocytokines; Polycystic ovary syndrome; Expression; Subcutaneous adipose tissue; Insulin resistance

\section{INTRODUCTION}

Adipose tissue is currently recognized as an endocrine organ because of its capacity to secrete adipokines, proteins that act as mediators of hormone action. Adipokines are involved in the regulation of glucose and fat metabolism, energy expenditure, inflammatory response, immunity, cardiovascular function, and reproduction (Henry and Clarke, 2008; Hausman and Barb, 2010).

Two specific adipokines - leptin and adiponectin - have been associated with body mass index (BMI), insulin action, and glucose metabolism. Leptin has been shown to act as an afferent satiety signal, regulating appetite and weight in humans and rodents (Zhang et al, 1994) by suppressing food intake and increasing energy consumption (Henry and Clarke, 2008). However, a missense mutation in the leptin or leptin receptor gene leads to severe obesity, demonstrating a physiological role of leptin in the regulation of metabolic homeostasis (Rahmouni, 2007). In turn, adiponectin increases fatty acid oxidation in adipose tissue, liver and muscle, enhancing insulin sensitivity, and inhibits inflammatory mediators and the expression of adhesion molecules within the vascular wall, lowering atherogenic risk (Chen et al., 2006; Michalakis and Segars, 2010). In women, the progressive increase in adiposity that occurs with age seems to influence the relationship between leptin and adiponectin: serum adiponectin levels decrease, while circulating leptin levels markedly increase with body fat mass (Lecke et al., 2011b).

Polycystic ovary syndrome (PCOS) is the most prevalent endocrine disorder in women of reproductive age, affecting 5 to $10 \%$ of women worldwide. It is characterized by hyperandrogenism and ovarian dysfunction, including oligo-anovulation and/or polycystic ovaries in the absence of other diseases affecting the pituitary and/or adrenal glands. PCOS is also a metabolic disorder, manifested by obesity, insulin resistance, dyslipidemia, and hypertension. These factors are associated with higher risk of type 2 diabetes and probably cardiovascular disease in PCOS patients. In fact, obesity, predominantly abdominal, is recognized as an important determinant of metabolic risk in these patients (Azziz et al, 2004; Spritzer and Wiltgen, 2007). In PCOS, elevated leptin serum levels have been associated with amount of adipose tissue, waist circumference, insulin resistance, and hyperandrogenemia (Spritzer et al., 2001; Carmina et al., 1999, 2005), while adiponectin levels have been reported to be decreased (Ardawi and Rouzi, 2005; EscobarMorreale, 2006; Jakubowska et al., 2008; Carmina et al., 2005, 2009) or unchanged (Orio et al., 2003; Sprangler et al., 2004; Gulcelik et al., 2006). In this paper, we briefly review the emerging evidence linking adipose tissue expression of leptin and adiponectin and serum adipokine levels in women with PCOS. 


\section{MATERIAL AND METHODS}

Circulating levels of leptin and adiponectin were determined by commercially available enzyme-linked immunosorbent assays with a coefficient of variation $<15 \%$. Adipose tissue total RNA was reverse-transcribed into complementary DNA samples, which were used as template for quantitative real-time PCR amplification as previously described (Carmina et al., 2008; Lecke et al., 2011a; Svendsen et al., 2012).

\section{RESULTS AND DISCUSSION}

Few studies have directly assessed fat gene expression of leptin and adiponectin in PCOS women (Carmina et al., 2008; Lecke et al., 2011a; Svendsen et al., 2012). Initially, Carmina et al. (2008) reported lower leptin and adiponectin gene expression in subcutaneous fat in women with PCOS vs weight matched controls. More recently, however, our group found that subcutaneous leptin mRNA was higher in overweight/obese PCOS women in comparison with normal-weight controls, with both groups stratified by BMI $\left(<\right.$ or $\left.\geq 25 \mathrm{~kg} / \mathrm{m}^{2}\right)$ (Lecke et al, 2011a). Using similar gene expression analysis, Svendsen et al. (2012) reached remarkably similar results, showing that even though subcutaneous leptin mRNA was higher in obese than in normal-weight women, obesity was associated with lower expression of subcutaneous adiponectin. Because each of these samples was from a different ethnic background, the difference between the initial study by Carmina et al. (2008) and the two later studies can only partially be explained by ethnic variation.

Confirming previous data, we found higher circulating levels of leptin in overweight/obese women with or without PCOS than in all normal-weight groups (Lecke et al., 2011a). Accordingly, Svendsen et al. (2012) also demonstrated that obesity was associated with increased plasma levels of leptin independently of the presence of PCOS. Both studies (Lecke et al., 2011a; Svendsen et al., 2012) showed similar serum adiponectin levels in all subgroups (normal-weight control vs normal-weight PCOS vs overweight/ obese control $v s$ overweight/obese PCOS).

Even though the protein expression of leptin and adiponectin in subcutaneous adipose tissue of PCOS women was not tested in any of these studies because of the scarcity of biological material, serum leptin and adiponectin levels could be interpreted as an indirect evidence of adipocyte production, since leptin and adiponectin are predominantly produced by subcutaneous adipocytes in women (Fain et al., 2004; Zha et al., 2009; Michalakis and Segars, 2010). Interestingly, we found positive correlations between serum and mRNA levels for both leptin $(\mathrm{r}=0.321 ; \mathrm{P}=0.005)$ and adiponectin $(\mathrm{r}=0.266 ; \mathrm{P}=$ 0.024). (Figure 1), reinforcing this hypothesis (Lecke et al., 2011a). Therefore, further studies are needed to specifically investigate the cause and effect direction between serum levels and fat gene expression for leptin and adiponectin with regard to metabolic and clinical variables in normal-weight and obese PCOS.

In conclusion, current data suggest that changes in adipokine gene expression in adipose tissue are related to adiposity rather than to hormonal disturbances in PCOS. Moreover, determination of serum leptin and adiponectin levels could be regarded as an indirect method to assess adipocyte production. 
A

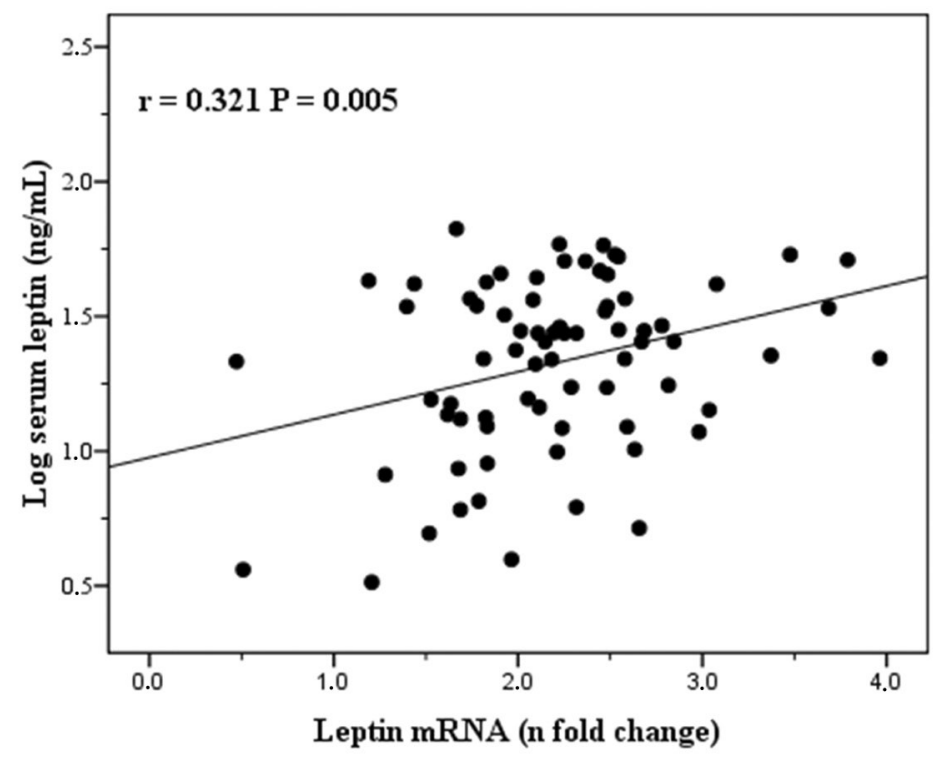

B

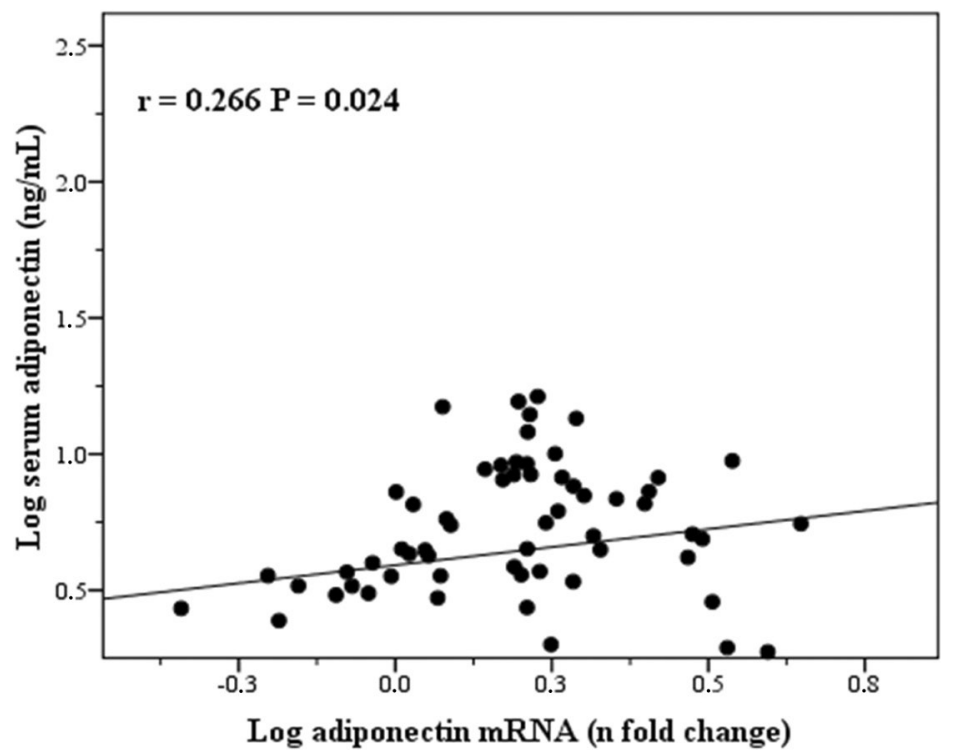

Figure 1. Correlation between serum levels and gene expression of leptin (A) and adiponectin $(\mathbf{B})$ in subcutaneous adipose tissue of women with polycystic ovary syndrome and controls $(\mathrm{N}=88$ women of reproductive age, with body mass index between 18.5 and $39.9 \mathrm{~kg} / \mathrm{m}^{2}$ ). mRNA was expressed as $\mathrm{n}$-fold change difference from the calibrator sample ( $\Delta \Delta \mathrm{CT}$ method). Pearson's rank correlation coefficients. Adapted from Lecke et al., 2011a,b).

\section{ACKNOWLEDGMENTS}

Research supported by Conselho Nacional de Desenvolvimento Científico e Tecnológico, 
Instituto Nacional de Hormônios e Saúde da Mulher (CNPq INCT \#573747/2008-3) and Fundo de Apoio à Pesquisa do Hospital de Clínicas de Porto Alegre (FIPE-HCPA \#110665), Brazil.

\section{REFERENCES}

Ardawi MS and Rouzi AA (2005). Plasma adiponectin and insulin resistance in women with polycystic ovary syndrome. Fertil. Steril. 83: 1708-1716.

Azziz R, Sanchez LA, Knochenhauer ES, Moran C, et al. (2004). Androgen excess in women: experience with over 1000 consecutive patients. J. Clin. Endocrinol. Metab. 89: 453-462.

Carmina E, Ferin M, Gonzalez F and Lobo RA (1999). Evidence that insulin and androgens may participate in the regulation of serum leptin levels in women. Fertil. Steril. 72: 926-931.

Carmina E, Orio F, Palomba S, Cascella T, et al. (2005). Evidence for altered adipocyte function in polycystic ovary syndrome. Eur. J. Endocrinol. 152: 389-394.

Carmina E, Chu MC, Moran C, Tortoriello D, et al. (2008). Subcutaneous and omental fat expression of adiponectin and leptin in women with polycystic ovary syndrome. Fertil. Steril. 89: 642-648.

Carmina E, Bucchieri S, Mansueto P, Rini G, et al. (2009). Circulating levels of adipose products and differences in fat distribution in the ovulatory and anovulatory phenotypes of polycystic ovary syndrome. Fertil. Steril. 91: 1332-1335.

Chen J, Tan B, Karteris E, Zervou S, et al. (2006). Secretion of adiponectin by human placenta: differential modulation of adiponectin and its receptors by cytokines. Diabetologia 49: 1292-1302.

Escobar-Morreale HF, Villuendas G, Botella-Carretero JI, Alvarez-Blasco F, et al. (2006). Adiponectin and resistin in PCOS: a clinical, biochemical and molecular genetic study. Hum. Reprod. 21: 2257-2265.

Fain JN, Madan AK, Hiler ML, Cheema P, et al. (2004). Comparison of the release of adipokines by adipose tissue, adipose tissue matrix, and adipocytes from visceral and subcutaneous abdominal adipose tissues of obese humans. Endocrinology 145: 2273-2282.

Gulcelik NE, Aral Y, Serter R, Demir Y, et al. (2006). Adiponectin is an independent determinant of insulin resistance in women with polycystic ovary syndrome. Gynecol. Endocrinol. 22: 511-515.

Hausman GJ and Barb CR (2010). Adipose tissue and the reproductive axis: biological aspects. Endocr. Dev. 19: 31-44.

Henry BA and Clarke IJ (2008). Adipose tissue hormones and the regulation of food intake. J. Neuroendocrinol. 20: 842-849.

Jakubowska J, Bohdanowicz-Pawlak A, Milewicz A, Szymczak J, et al. (2008). Plasma cytokines in obese women with polycystic ovary syndrome, before and after metformin treatment. Gynecol. Endocrinol. 24: 378-384.

Lecke SB, Mattei F, Morsch DM and Spritzer PM (2011a). Abdominal subcutaneous fat gene expression and circulating levels of leptin and adiponectin in polycystic ovary syndrome. Fertil. Steril. 95: 2044-2049.

Lecke SB, Morsch DM and Spritzer PM (2011b). Leptin and adiponectin in the female life course. Braz. J. Med. Biol. Res. 44: 381-387.

Michalakis KG and Segars JH (2010). The role of adiponectin in reproduction: from polycystic ovary syndrome to assisted reproduction. Fertil. Steril. 94: 1949-1957.

Orio F, Jr., Palomba S, Cascella T, Milan G, et al. (2003). Adiponectin levels in women with polycystic ovary syndrome. J. Clin. Endocrinol. Metab. 88: 2619-2623.

Rahmouni K (2007). Differential control of the sympathetic nervous system by leptin: implications for obesity. Clin. Exp. Pharmacol. Physiol. Suppl. (Suppl 34): S8-S10.

Spranger J, Mohlig M, Wegewitz U, Ristow M, et al. (2004). Adiponectin is independently associated with insulin sensitivity in women with polycystic ovary syndrome. Clin. Endocrinol. 61: 738-746.

Spritzer PM and Wiltgen D (2007). Prevalence of metabolic syndrome in patients of south of Brazil with polycystic ovary syndrome (PCOS). Arq. Bras. Endocrinol. Metabol. 51: 146-147.

Spritzer PM, Poy M, Wiltgen D, Mylius LS, et al. (2001). Leptin concentrations in hirsute women with polycystic ovary syndrome or idiopathic hirsutism: influence on LH and relationship with hormonal, metabolic, and anthropometric measurements. Hum. Reprod. 16: 1340-1346.

Svendsen PF, Christiansen M, Hedley PL, Nilas L, et al. (2012). Adipose expression of adipocytokines in women with polycystic ovary syndrome. Fertil. Steril. 98: 235-241.

Zha JM, Di WJ, Zhu T, Xie Y, et al. (2009). Comparison of gene transcription between subcutaneous and visceral adipose tissue in Chinese adults. Endocr. J. 56: 935-944.

Zhang Y, Proenca R, Maffei M, Barone M, et al. (1994). Positional cloning of the mouse obese gene and its human homologue. Nature 372: 425-432. 